Concept Paper

\title{
Disrupting the Disruption: A Digital Learning HeXie Ecology Model
}

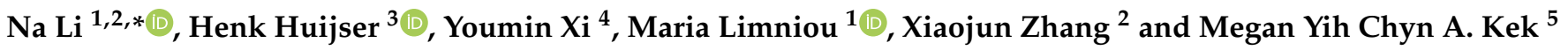 \\ 1 Department of Psychology, University of Liverpool, Liverpool L69 7ZA, UK; maria.limniou@liverpool.ac.uk \\ 2 Academy of Future Education, Xi'an Jiaotong-Liverpool University, Suzhou 215123, China; \\ xiaojun.zhang@xjtlu.edu.cn \\ 3 Learning and Teaching Unit, Queensland University of Technology, Brisbane, QLD 4000, Australia; \\ h.huijser@qut.edu.au \\ 4 HeXie Management Center, Xi'an Jiaotong-Liverpool University, Suzhou 215123, China; \\ youmin.xi@xjtlu.edu.cn \\ 5 The Institute of International Studies, Sydney, NSW 2000, Australia; megan.kek@tiis.edu.au \\ * Correspondence: nali2@liverpool.ac.uk or na.li@xjtlu.edu.cn
}

check for updates

Citation: Li, N.; Huijser, H.; Xi, Y.; Limniou, M.; Zhang, X.; Kek, M.Y.C.A. Disrupting the Disruption: A Digital Learning HeXie Ecology Model. Educ. Sci. 2022, 12, 63. https://doi.org/10.3390/ educsci12020063

Academic Editor: Margus Pedaste

Received: 16 December 2021

Accepted: 14 January 2022

Published: 18 January 2022

Publisher's Note: MDPI stays neutral with regard to jurisdictional claims in published maps and institutional affiliations.

Copyright: (C) 2022 by the authors. Licensee MDPI, Basel, Switzerland. This article is an open access article distributed under the terms and conditions of the Creative Commons Attribution (CC BY) license (https:// creativecommons.org/licenses/by/ $4.0 /)$.

\begin{abstract}
Broad societal disruptions (i.e., the industrial revolution, digitalisation, and globalisation) have created a need for an increasingly adaptive higher education system in recent decades. However, the response to these disruptions by universities has generally been slow. Most recently, online learning environments have had to be leveraged by universities to overcome the difficulties in teaching and learning due to COVID-19 restrictions. Thus, universities have had to explore and adopt all potential digital learning opportunities that are able to keep students and teachers engaged in a short period. This paper proposes a digital learning HeXie ecology model, which conceptualises elements and relationships pertaining to the societal need for a more agile and digitally resilient higher education system that is better placed to confront disruptive events (such as pandemics) and that is able to produce graduates who are well-equipped to deal with disruption and uncertainty more broadly. Specifically, we propose a digital learning ecology that emphasises the role of selfdirected learning and its dynamic interaction between formal, informal, and lifelong learning across a five-level ecosystem: the microsystem, mesosystem, exosystem, macrosystem, and chronosystem. This study contributes to the theoretical literature related to flexible learning ecologies by adopting and incorporating the Chinese HeXie concept into such ecologies.
\end{abstract}

Keywords: digital learning ecology; self-directed learning; learning technology; digital resilience; higher education; HeXie

\section{Introduction}

Building on the Fourth Industrial Revolution [1], Globalization 4.0 [2] has provided opportunities for industry and education to enhance their connections and collaboration, allowing higher education institutions to reconsider their business models, learning environments, technologies, and pedagogies in the process [3,4]. However, most universities have, until recently, been rather cautious about the continuous disruptions (e.g., new learning technologies, rapidly changing market demands, and political rules) and potential educational transformations [5,6]. This situation changed dramatically in 2020 through the enforced impact of COVID-19. "Across the globe, higher education institutions have been radically reshaping teaching and learning in unprecedented ways, and with rare exceptions, education has moved into the online space at breakneck speed" [7]. It is not that the opportunities have not been there to leverage online environments extensively before 2020, but universities as large organisations tend to be relatively conservative and change-averse. COVID-19 has forced considerable changes and disruptions, such as the determinants of students' perceived learning outcomes and their satisfaction in online 
learning [8] and learner-content interactions [9]. At this stage, it is difficult to predict where these changes will ultimately lead.

It is almost certain that we will see a significant decrease for at least the next two years in the numbers of students undertaking study abroad and exchange, and it is likely that, during this period, Virtual Exchange will become the new normal [10] (p. 2).

Slow educational changes, especially when they can be seen to lag behind changes in wider society [4], have consequences for educational outcomes themselves, and the disruption caused by COVID-19 may therefore present somewhat of a silver lining in an educational context [11]. In the end, it may be the disruption needed to cause an educational disruption, through which university education is opened up to a wider learning ecology [12]. The concept of a learning ecology is "consistent with the Gestalt tradition, as part of which the [Bronfenbrenner's] human ecology development model was developed, [whereby] the whole is larger than the sum of its parts" [13] (p. 5). Such an ecology has the potential to promote learner empowerment in terms of self-directing their learning pathways [14], as it would include the formal learning environment of universities (both face-to-face and in the form of formal structures such as learning management systems or virtual learning environments), but it would also connect seamlessly to the plethora of learning opportunities outside of the formal higher education system, including digital learning spaces and platforms on the web [12].

The COVID-19 pandemic has caused a disruption to higher education that may allow for such a learning ecology to emerge. Salmon [3] argues that the digital revolution has created considerable freedom of access to information. In the context of open universities,

\section{It [the digital revolution] poses challenges but also opens up unprecedented opportunities for democratisation and accessibility. The transformation process has to maintain the referential of the profound incorporation of pedagogical and technological innovation based on research and seek new strategies of organisation and definition of quality, to guarantee its relevance and leadership in the pursuit of the massification of higher education [15] (p. 191).}

As a result of the digital revolution, the knowledge students engage with within universities becomes outdated more quickly due to accelerated innovation and knowledge development rates and is aided by ever-faster digital networks. Next-generation digital learning environments have been proposed by educational technology practitioners to create a transformational shift in how universities design their learning ecosystems for students and teachers to have higher levels of digital resilience [16]. Multiple disruptions imply that our conceptualisation of learning and teaching may need to change accordingly if we are to seize the learning opportunities that contemporary digital environments provide [17-21]. "The agility provided by such an architecture can afford learners and instructors alike the opportunity to 'think outside the box', and reconceptualise their approaches to education" [22]. Society requires a more adaptive learning ecosystem to increase learners competence in a changing environment, to strengthen universities' resilience in disruptions, and to reshape lifelong and life-wide education with on-demand, tailored, and personalised learning elements.

To address the question of how future universities could develop digital resilience to become more prepared for subsequent disruptions, this paper synthesized a conceptual model based on the Problem-Based Learning (PBL) ecology [13] with an extended layer of the Chinese HeXie concept [23]. The model highlights the role of self-directed learning and digital resilience through formal, informal, and lifelong learning across a five-level ecosystem: the microsystem, mesosystem, exosystem, macrosystem, and chronosystem. It has been suggested that the nature of higher education is "to enable society to make progress through an understanding of itself and its world" [24], which implies that universities are separate from society but are capable of improving society from their enlightened position. This paper discusses the significant but blurred lines of a learning ecology, as it can be seen as a paradox that an inherently conservative higher education system is positioned as 
being able to advance society in innovative ways. This study contributes to the literature by emphasizing that higher education has the potential to occupy that position, but only if it is integrated, in agile and reciprocal ways, into the society it is meant to impact and vice versa. In other words, the boundaries and the constraints would need to be significantly blurred and become much more porous so that continuous exchanges and dynamic interactions between universities and their societal contexts become possible.

\section{Materials and Methods}

This conceptual study employs a theory synthesis method to "achieve conceptual integration across multiple theories or literature streams" and aims to "offer a new or enhanced view of a concept or phenomenon by linking previously unconnected or incompatible pieces in a novel way" [25]. Following Weick's [26] theoretical model development strategy, this paper first reviews the extant literature to identify problems and challenges; second, it summarizes the theoretical model development needs and develops the research question.

\subsection{Challenges in Formal Learning Environments in the Digital Era}

In the past thirty years, formal learning has been "institutionally sponsored, classroombased, and highly structured" [27]. Universities provide formal learning environments to facilitate institutionalised, chronologically graded, and hierarchically structured formal educational systems [28]. The key assumption in the traditional conceptualisation of formal learning environments has been that learning can be delivered or provided in a discrete, packaged manner, which is timed and clearly demarcated, and symbolised by the walls of the physical classroom and semester timetables [29]. With the development of the World Wide Web (Web 1.0), the emergence of Virtual Learning Environments (VLEs) [30,31] extended formal learning beyond the physical classroom to an online environment with interactive activities, albeit a walled and password-protected one.

McGuire and Gubbins [32] have argued that formal learning has been supplanted by activity-based and technology-based learning, suggesting that activity-based and technologybased learning are not formal learning. However, this is a limited conceptualisation of formal learning in modern digital learning environments. In other words, formal online learning environments, if designed in particular ways, can be characterised by activity-based learning approaches, if often within the walled garden of the VLEs. Thus, the emphasis should not so much be on supplanting formal education but on leveraging informal learning through innovative learning design to make learning overall more effective. Any approaches that could provide students with the systematic knowledge that they require to operate within complex structures [33] beyond their formal studies and that provide sufficient support during knowledge acquisition [34] could be recognised as formal learning.

During the COVID-19 pandemic, students have relied on technology-based formal learning more than ever [35]. In fact, digital disruption had started long before the pandemic caused an additional disruption [36]. Students have long been digitally connected in their everyday digital environments, which, in many ways, could be seen as informal learning spaces. During the pandemic, for example, students have been required to use their mobile devices to attend online lectures from isolated locations (i.e., home, student accommodation) and to engage in online assessment activities $[37,38]$. These can all be seen as formal learning. However, the same devices give students access to a much wider digital environment that provides potentially endless opportunities for learning beyond the formal learning context, or indeed for deliberately integrating such opportunities into the formal learning environment [39].

A common assumption is that formal intentional learning is more standardized and should be supported by technologies that are designed for educational purposes [40]. This assumption has stopped educational institutions from investigating the possibilities of using or leveraging disruptive technologies to enhance learning and teaching and to even stimulate cutting edge innovation in education [36]. In other words, there is a tendency to categorise digital technologies into particular boxes such as education, communication, or 
social media, whereas in reality, the lines between them are blurred. Moreover, students will have to use and learn how to use a wide variety of technologies when they graduate and upon entering employment or enterprise environments [41]. This suggests that we need a wider conceptualisation of educational technologies, one that recognises the potential of the overall digital environment as a learning environment, rather than just the formal one. The latest pandemic-induced disruption may serve as a catalyst for that kind of reconceptualization [35].

Centrally supported educational technologies are under institutional control and are characterised by limited uncertainty and high levels of standardization [40]. By promoting the use of these supported centralised technologies, the university can provide institutional support with relatively few resources because their use is predictable and contained [42]. From a business model perspective, there are institutional pressures for high efficiency and limited uncertainty, which explains the attraction of the notion of supported centralised technologies and the resistance to the use of external and potentially disruptive technologies [36]. However, standardisation is sometimes the enemy of creativity and agility, which are some of the key attributes we expect students to graduate with $[13,43]$. This raises the question of whether a standardised digital environment is capable of preparing students for life beyond their degree studies, which likely involves complex and constantly evolving contexts that require continuous searching for new opportunities and digital tools for business, for creative solutions, and thus for learning.

An example of a learning technology that is instructionally controlled is Virtual Learning Environments (VLEs), which have been adopted by various universities to support teaching and learning [42]. VLEs, as the institutional technologies that define formal learning environments, have largely reproduced, rather than disrupted or transformed, learning and teaching practices [44]. Many studies have revealed that technologies provided by universities for formal learning have not been globally successful in terms of adoption and usage to justify their huge investment [32,45-47]. Teachers and students prefer convenient and easy-to-use technologies, despite many of these technologies not being designed for educational purposes (e.g., Zoom, Microsoft Teams) and despite lacking institutional support [48]. Universities are positioned to remind teachers and students of the coexistence of institutionally supported and non-supported technologies [49]. For example, the ABC learning development framework of the University College London (UCL) has highlighted three types of the learning technologies: UCL supported, provided with limited or no support, and support provided locally in the division/department [50]. The educational transformation of both teachers and students is crucial in the digital learning ecology so that they can feel comfortable using technology for learning and teaching, regardless of whether the university supports it or not [51].

However, the contribution from these non-institutional disruptive technologies is largely unexamined [48]. For example, employers (i.e., industry and small companies) require graduates to work efficiently with many useful technologies and sometimes highly specialised technologies [41,52]. Many of these technologies may not be commonly used in universities for learning and teaching, such as Facebook, Slack, or a whole range of mobile apps [53]. Of course, it is impossible to adopt all possible technologies in a formal learning environment. Yet, it is possible to infuse the curriculum and learning approaches at university with the development of the students' ability to adopt and adapt to new technologies wherever possible and relevant. In this digital era, students should be adaptive to the use of a wide variety of technologies for both their learning and their future careers $[54,55]$.

\subsection{New Opportunities in Informal and Lifelong Learning Environments in the Digital Era}

The business model of higher education has changed over the years due to marketisation [56,57], which started with mass higher education [58], the introduction of student tuition fees, and the trend of universities selling teaching and research as services with increasing student numbers and reduced budgets [58-61]; the granting of university status to polytechnic colleges [4,59-61]; and the spread of the (UK) Open University model [62]. 
At the same time, deeper collaborations with industry are sought to reduce the mismatch of the students' employability and the employers' expectations, for example by focusing on entrepreneurial skills [63,64] or through work-integrated learning initiatives [65]. Future education will not be limited to the above models, and a new social contract for education is needed [66].

New models of learning emerged during the COVID-19 pandemic, providing additional opportunities for private contractors / partners to work more closely with universities and enhancing collaborations in innovative learning design that leverage a wider learning ecology [67]. For instance, the University of Illinois at Chicago has started a universityindustry partnership in developing hybrid courses based in their VLE [39]. In China, Xi'an Jiaotong-Liverpool University (XJTLU) is piloting several new educational models, such as the "learning mall", with an integration of the physical campus, deep partnership with industry for syntegrative education, and online education [23]. Syntegrative education is a new education model that XJTLU has used to develop globally competitive citizens and to provide opportunities for students to work in the industry alongside their degree, gaining industrial certificates and practical skills during the learning process [23]. This has further opened a door for both universities and private partners to explore the possibilities of crossing the boundaries of informal and formal learning with seamless digital integrations between (and beyond) formal digital learning environments.

\subsection{The Need for a Reconceptualized Model}

Teacher-centred learning has been largely dominant in modern universities, and perhaps even more so since the massification of higher education [68]. Following the traditional way of teaching, teachers usually act as a "sage on a stage", transmitting knowledge and information to students in a unilateral direction [3,5]. Inspired by constructivist views on learning [69], more student-centred learning environments have emerged to encourage greater participation and collaboration between students who are required to take more responsibility for their formal, informal, and lifelong learning [70-74].

The extant literature has raised questions on how teachers could change teaching approaches by adopting a more student-centrered one, e.g., [11,73]. However, on the one hand, the pandemic-related disruption has led teachers to adopt different teaching approaches [75], while on the other hand, it may have added considerable stress to those teachers lack digital resilience during the COVID-19 pandemic [76].

There is an increasing recognition of the link between student-centred approaches and active learning process that is related to self-directed learning [73]. Since Tough's [77] adult learning research project, the study of self-directed learning (SDL) has taken an adult focus, emphasising learner characteristics [78,79] and the instructional process [80-82]. Self-directed learning readiness has been defined as the degree to which the individual possesses the attitudes, abilities, and personality characteristics necessary for self-directed learning [83].

In summary, the major problems encountered in our literature review were the lack of a comprehensive theoretical model to build agile, responsive, and proactive approaches to developing student self-directed learning competencies across formal, informal, and lifelong learning environments in the digital era [73]. More recently, a growing body of literature has begun to identify the need to address self-directed learning across a lifespan in formal and informal learning environments $[84,85]$. To develop students' self-directed learning capabilities, teachers need a reconceptualisation of learning environments that would make them not only fit for purpose but that would also "force" teachers to focus more on what fit of purpose is [86]. Regarding the challenges that teachers may face due to a potential disruption, this distinction raises a question: how could future universities gain digital resilience to disrupt the disruption? To answer this question, a digital learning HeXie ecology model has been proposed to build agile, responsive, and proactive approaches to develop students' self-directed learning competence. 


\section{The Digital Learning HeXie Ecology Model}

This paper proposes a digital learning HeXie ecology model to cover the need for agile education with a focus on self-directed learning and digital resilience. The proposed model conceptualises not only the fluidity between formal, informal, and lifelong learning between the teacher and student, but it also supports a dynamic balance of the learning ecology through the HeXie education model (see Figure 1). Further, the proposed model is based on the five levels of Bronfenbrenner's [87] human ecology, which was further developed in Kek and Huijser [13] agile Problem-Based Learning (PBL) ecology for learning. As an active learning approach, PBL "leverage[s] different systems in the agile ecology for learning [and] serve[s] as a curricular and pedagogical vehicle to facilitate the development of a particular way-of-being among students" [43], which includes skills and attributes such as critical reflection and creativity. The proposed model has additionally incorporated the HeXie concept, which supports higher education institutions to adopt an approach to overcome the challenges posed by potential disruptions (i.e., COVID-19) by focusing on the need to continually re-balance.

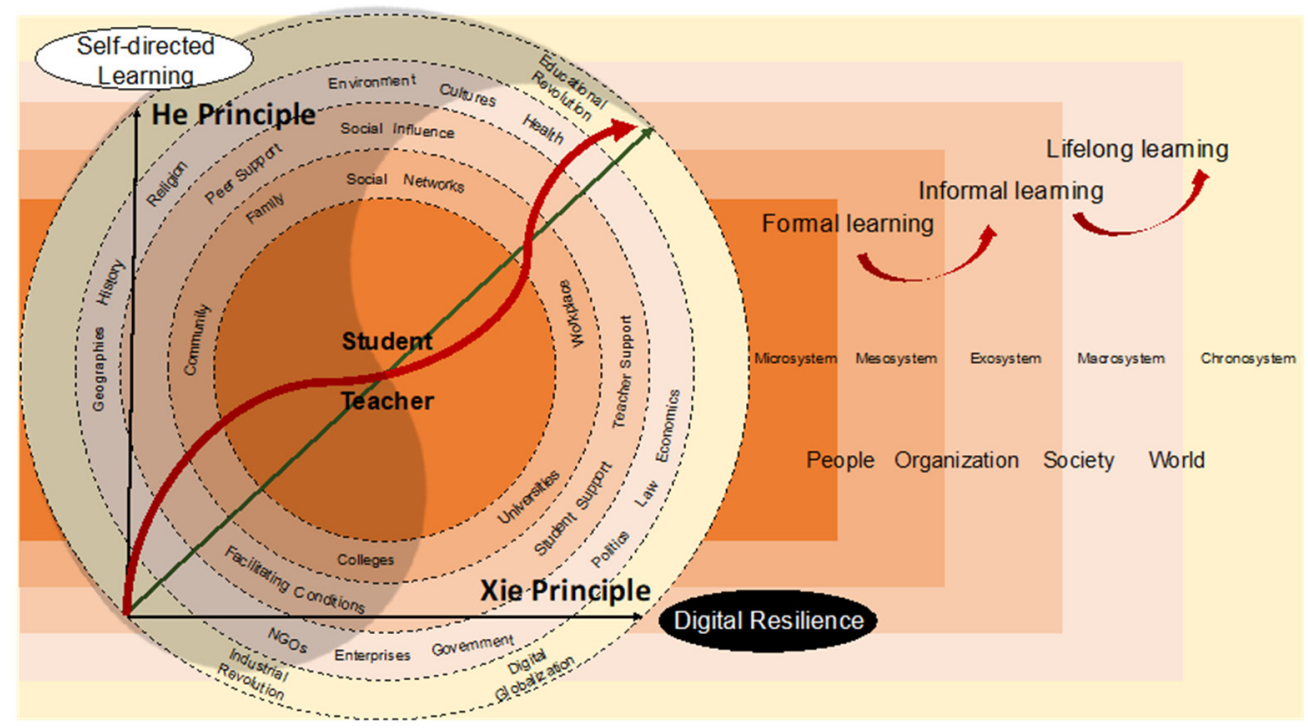

Figure 1. Digital learning HeXie ecology model, adapted from Kek and Huijser's agile PBL learning ecology [13] and Xi's HeXie education model [23].

\subsection{Self-Directed Learning in the Digital Learning Ecology}

Following Carré [88] research, we define self-directed learning as a dynamic combination of two dimensions: self-determined motivation to learn and self-regulation strategies and abilities in learning. Self-regulation refers to the abilities and strategies of selfregulation in learning, while self-determination refers to self-determined motivation to learn. When confronted with the COVID-19 disruption, many universities rapidly changed from low digital context traditional learning to high digital context online learning $[35,89]$. Students with higher level digital resilience and greater self-directed learning readiness could adjust themselves [90] in the relatively isolated online learning environment by using digital learning technologies, e.g., an online calendar for time management, online tutorials to seek feedback from teachers, online peer support forums to discuss common issues and share information, and a range of other digital tools and resources that do not form part of the formal learning environment in a strict sense [89].

The digital transformation of higher education may connect students' digital resilience with their self-directed learning readiness. This invites important caveats for it to work: firstly, students need to be digitally connected and capable, which means that they need to be comfortable in navigating the potential that a digital learning ecology offers [13]. Secondly, there can be no assumption that self-directed learning simply happens because 
students find themselves in a digital learning ecology. Instead, self-directed learning needs to be deliberately designed into formal learning environments and deliberately taught [73].

As noted, the boundary between formal and informal learning environments is becoming increasingly blurred. However, the distinction between formal and informal learning environments is still rigidly maintained in many ways, as change is resisted and institutions hold on to the ways they have always done things [91]. Yet, the recent COVID-19 disruption may have accelerated the exploration of a more expansive learning ecology that encourages higher level self-directed learning across formal and informal learning environments. For example, in flipped classrooms, students can watch lecture videos or access learning resources provided in the formal learning environment, while well-designed formal learning environments will, at the same time, allow students to explore and draw on their sources for learning in informal learning environments [92].

In this way, they have opportunities to ask questions and formally collaborate with peers in solving problems in a lab or classroom (formal learning in the formal environment), but they can also simultaneously engage with other resources (and other learners) in informal digital learning environments. Indeed, this would be encouraged. The quick development of mobile technologies has enriched the learning opportunities in informal learning environments, as many students have ubiquitous access to digital learning [93]. Watching a 2 min video explaining the epidemic R-nought on a cell phone while taking a bus is a common format of informal learning. Students construct their knowledge both from learning in an informal environment and in a formal environment. Self-directed learning is therefore a competence the student needs to develop urgently as a key stakeholder, for which teachers as the other key stakeholders need to take responsibility.

\subsection{Digital Resilience in the Digital Learning Ecology}

Formal and centralised technologies may take time to catch up to disruptive situations [94], but in the learning ecology that we discuss in this paper, teachers and students as key stakeholders can use alternative solutions in an agile manner, which creates considerable resilience in the overall learning environment. Although some of these technologies are not specifically designed for educational purposes, they can be used as part of the educational process, which adds authenticity in terms of what students will ultimately need to be able to do when they graduate. The transition from previous education modes to a new educational model in response to disruption is reliant on effective processes for the incorporation of a wide and ever-expanding range of technologies into the learning process. The biggest challenges include the continuous administrative burden of managing user accounts, keeping equal accessibility, providing user training, and support for different technologies.

However, in a disrupted learning environment, this is no longer solely an institutional responsibility, but instead becomes a responsibility of everyone in the learning ecology, including students and teachers as the key stakeholders. In current formal learning environments, teachers and students alike become easily confused if clear instructions on how to use different technologies for different learning and teaching activities are not provided in advance, as the expectation is that institutions provide both the technology and the training. We are suggesting here that this responsibility needs to shift if universities are to become more digitally resilient and to become better positioned to deal with disruptions in the future.

In addition, the richness of digital technology and the use of a wide range of alternative solutions beyond formal learning management systems could increase the university's digital resilience in supporting formal and informal learning and teaching. When disruptions occur, such as the COVID-19 pandemic, universities with limited digital resilience may face different challenges (e.g., lack of solid digital infrastructure to support large group synchronous online learning). For example, given their different levels of technology adoption and the very limited preparation time, some universities hardly have had any centralised technologies at all throughout the COVID-19 pandemic [95-97]. Universities 
were thus forced to use whatever technologies were available (e.g., a range of different online conferencing technologies) to facilitate online learning and to address the main problem of a lack of interaction with students.

On the other hand, universities that had already implemented centralised technologies for a long time might have had a strong reliance on rigidified institutionalised practices [98]. It usually takes longer to make changes and upgrade existing technologies that form part of rigidified institutional infrastructures [99]. Thus, when disruption occurs, these institutions are often not agile enough to respond. By contrast, an agile educational ecology includes any potential digital tool that can be leveraged to support flexible learning. However, to actually leverage such digital tools requires astute learning designers to collaborate with academic content experts to develop a responsive, proactive, and agile learning design that is student-centred and that draws on both digital environments and tools that students are already familiar with and ones that they need to become familiar with. In short, such learning design oscillates between the push and pull of a range of ever-changing tools in a hugely dynamic and constantly disruptive digital (learning) environment. The word learning is in parentheses, as a digital environment requires deliberate design to become an effective learning environment.

\subsection{HeXie Education Model in the Digital Learning Ecology}

In the digital learning ecology, the HeXie education model reflects both oriental and occidental wisdom in education. Figure 2 illustrates the full version of the HeXie education model [23] that our digital learning HeXie ecology model has integrated. The concept of "HeXie" originated from Chinese Confucianism (emphasis on harmony) [100,101] and Daoism (with an emphasis on the Yin and Yang balance) [102]. The HeXie education model was developed based on the HeXie theory $[103,104]$ to couple formal and informal learning based on a lifelong plan with three steps: learning, growth, and conduct. The He principle emphasizes the importance of self-directed learning for innovative and dynamic actions, while the Xie principle focuses on design and planning for digital resilience. The two principles are coupled throughout lifespan through three main steps (learning, growing, and conducting) in a mix of five learning types (inheritance learning, reflective cognition, exploratory integration, interest driven accumulation, and mindset upgraded progress) to achieve the long-term vision and mission of the ability to face a rapidly changing world [23].

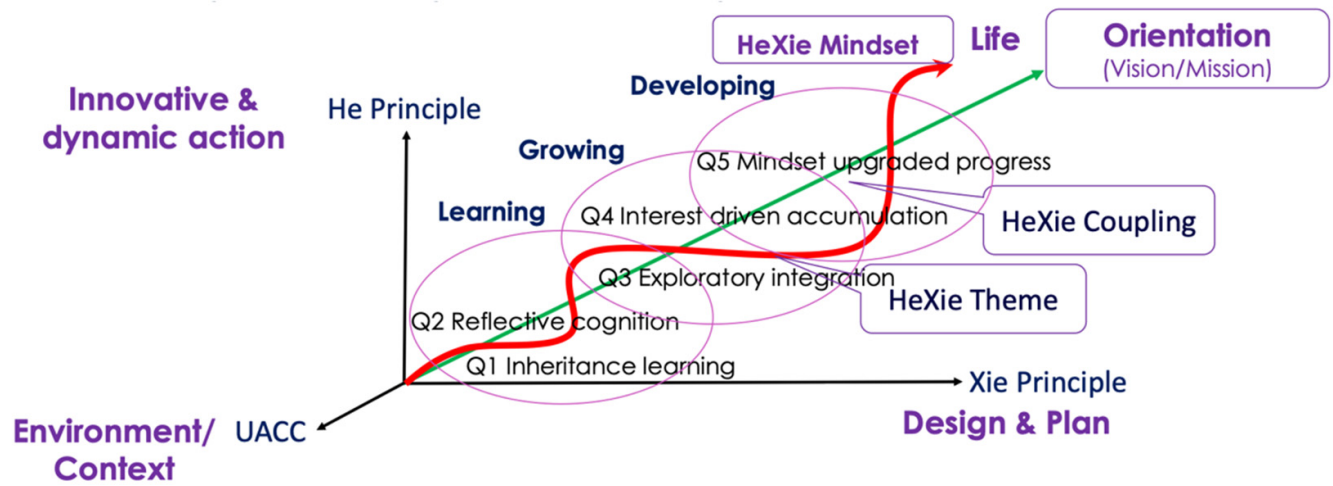

Figure 2. Adapted from Xi's HeXie education model [23].

The UACC in Figure 2 refers to uncertainty [105], ambiguity [104], changeability [91], and complexity [106]. Whatever disruptions we are facing, the essence of education is to help students understand themselves and to have a vision and mission or life orientation. The digital learning ecology aims to help students learn knowledge and gain the capability to follow their dreams in a practical sense, while the life orientation is the intrinsic motivation for learning. In the original HeXie Management Theory [103,104], the HeXie Theme refers to the key tasks or core business faced by the key stakeholders in a specific period. 
Key stakeholders will need careful consideration about using the two principles to carry out the task or solve the problem.

In the educational context, the HeXie Theme refers to the key learning tasks a student needs to perform at different learning stages. During their learning journey, students might face various challenges when taking on different learning tasks for certain periods (e.g., for undergraduate students, year 1-2 as a freshman or sophomore, year 3-4 as a senior student). Different HeXie Themes will need different activities to help students implement the plan or to carry out specific learning tasks. Students are encouraged to critically think about the unique features of specific learning tasks and how they could use the two principles (He or Xie or both) and couple them with the HeXie Theme to develop themselves to achieve higher-level life orientation. For example, the Xie principle could better support learning with technologies (e.g., in-class polling or AI grading) to help with prior knowledge and explicit memory-focused learning. By contrast, the $\mathrm{He}$ principle could encourage critical thinking for the reflective cognition of the real world, which requires higher learner autonomy. In a flipped classroom setting, the two principles are both required to foster a self-directed, exploratory, constructive, active, experiential, research-led, and syntegrative learning environment.

In higher-level learning, such as self-interest driven accumulation towards ideals, competence development as a global citizen, and interdisciplinary collaboration to address 'wicked problems' collectively (e.g., climate change), students will need to develop a growth mindset [107] that aligns with the HeXie mindset. The HeXie mindset can be developed or nurtured by embracing the ontological and epistemological framework that originated from HeXie Management Theory as a complex problem-solving paradigm. When facing a changing world with the UACC challenges, students will need to clearly understand their life orientation (i.e., vision and mission). Furthermore, they will need to set the core objectives and identify the key learning tasks for each learning stage. Through the dual rationality provided by the $\mathrm{He}$ and Xie principles, students can benefit from the Xie principle's systematic support (e.g., institutions, processes and technologies). The He principle can help students make better use of the policies, culture, and emotions to develop a selfdirected learning ability and co-create a humanistic learning environment with teachers and other stakeholders. Through HeXie coupling, students can work towards a vision, optimise, and evolve dynamically based on the HeXie Theme at each stage. Therefore, the HeXie mindset is critical to help students adapt to a future-oriented perspective, while integrating the wisdom of the West and East to find the theme in each stage and to address new trends and issues [23].

\subsection{The Five Levels of the Digital Learning Ecology}

Bronfenbrenner's five levels consist of the microsystem, the mesosystem, the exosystem, the macrosystem, and the chronosystem. The following section explains the five levels of the digital learning using the HeXie ecology model.

\subsubsection{Microsystem}

The microsystem refers to the formal learning environment where students engage with or are confronted with the curriculum design, physical learning spaces, teachers, and assessment as well as formal digital (or virtual) learning spaces, such as the learning management system, the online enrolment system, and so on. In other words, the microsystem is what we often think of as the university learning environment in a narrow sense. It relates to learning spaces where teachers and students engage with each other directly [108]. It also includes pedagogy, formal learning technologies, and self-directed learning [109], if the latter is indeed designed into the learning environment. This might be influenced by individual factors such as age, emotion, (prior) knowledge, experience, and mindset [99]. Each of these could, in turn, be affected by institutional factors, cultures, and social backgrounds in the mesosystem [43]. 


\subsubsection{Mesosystem}

The mesosystem level reflects a wider system of connections that include higher education institutions, family, workplaces, social networks, and the wider community [110]. Digital technologies may straddle the boundaries between the microsystem and the mesosystem. For example, university students who have early access to the technologies that are the most commonly used in workplaces might have a greater opportunity to find jobs [54]. However, a university student's socio-economic status, which is connected to family income, may influence their attitude (i.e., self-determination) and ability (i.e., selfregulation) to afford the devices and internet access needed to be able to use technology in formal or informal learning environments (social network and community) [111,112]. University-supported centralised learning technologies could provide students with institutionally licensed services and learning spaces without extra personal cost. These open-source or cheap disrupting learning technologies can serve as alternatives and flexible supplements when centralised technologies encounter disruption. Therefore, when higher education institutions make decisions about technologies and the institutional facilitation of technology-enhanced learning, factors such as access, equality, student employability, and social sustainability need to be considered to reduce the digital divide [39].

\subsubsection{Exosystem}

The exosystem refers to the broader support systems in the learning ecology, both formal and informal, and again, the boundaries between them are often blurred and fluid. This broader support system includes elements such as co-curricular student support (e.g., digital literacy, technology troubleshooting, user guides, instructions from teachers, teacher attitudes, institutional norms, regulations, culture, and cognition), teacher support (e.g., technology troubleshooting, user guides, professional development, student feedback, learning analytics, institutional norms, regulations, culture, and cognition), peer support (e.g., knowledge sharing, peer influence), facilitating conditions (e.g., supported VLE, disruptive technologies, organisational structures, resources), and social influence (e.g., social norms, morality, culture). Leveraging this kind of available support requires initiative and proactive help-seeking where needed; in short, it requires self-directed learning skills, as discussed earlier.

\subsubsection{Macrosystem}

The macrosystem is the wider context in which the learning ecology is situated, for example on a state, national, or global level. Thus, it includes the economy, government, enterprise, non-profit organisations, the natural environment, geographies, religion, culture, health, law, politics, and history. Clearly, during the disruption caused by the COVID-19 pandemic, the macrosystem has become more salient, but it affects all other systems to varying degrees. For example, universities became dependent on government regulations around international travel (e.g., with regard to international students), and they became dependent on government funding (or lack thereof) to cover some of the losses caused by students not being able to travel and come to a physical campus [39]. Again, within the learning ecology thus conceptualised, the notion of self-directed learning becomes very relevant, as it underlies the broader idea of developing lifelong learners who are agile, responsive, and proactive to rapidly changing contexts, including potential disruptions. For example, in a major disruptive event such as COVID-19, self-directed learners would be able to quickly adapt to changing circumstance by developing their digital capabilities by quickly learning new online tools to help them continue their learning in a digital environment [113].

\subsubsection{Chronosystem}

Finally, the chronosystem refers to broader, historical movements, and indeed, disruptions, including, for example, the industrial revolution [1], the massification of higher education on a global scale [56], and digital globalization [114]. For example, the earlier 
referred to Globalisation 4.0 [3] would fit into the chronosystem, with a fluid spill-over into the macrosystem. Thus, the chronosystem refers to broad, often generational changes that occur at various points in time, which then have a major (often disruptive) impact. In some cases, they may be seen as paradigm shifts. The emergence of big data over the last decade is one example, and the impact of AI may be another that is still developing [4]. Prior to that, the arrival of the World Wide Web in the 1990s and social media in the first decade of this century constitute other examples [3]. These types of disruptions can be mapped to particular eras, and the responses to them tend to be significant changes in the way higher education is approached. Again, self-directed learning is the central thread that cuts across the different systems as both a way of buffering against disruptions (and hence a form of resilience) and as a way of leveraging the potential that such disruptions may afford.

\subsection{Balancing the Disruption in the Digital Learning Ecology}

The five systems that make up the learning ecology go through periods of relative calm, even if they are in constant flux. When considering large-scale disruptions, however, another layer could be added to the aforementioned learning ecology, which would be focused on keeping a balance between the situations prior to the disruption and the postdisruption context. The static view examines how a system and its parts behave under a state of equilibrium, while all of the forces affecting it are in a dynamic balance [115]. However, during a disruptive event, each element moves under the influence of forces that push it toward, away from, or between equilibria [116]. The Chinese concept of HeXie could overlay the learning ecology, as it draws attention to how balance can be restored in response to disruption, or more importantly, how a new and ideally more productive and relevant balance may be achieved. The balance here is universal, and other models have explored similar system thinking perspectives, such as Beer's Viable Systems Model [117] and Kaufman's Organizational Elements Model [118].

Overall, the proposed model in Figure 1 illustrates how HeXie education model is focused on the balance between each of the broad elements that relate to student learning in the overall digital learning ecology. The ecology itself is circular, which means that we can start anywhere at any time, and the relationships are dynamic, depending on where we choose to target our analytical focus. In response to disruptions, however, each of the five systems in the learning ecology affects the others to varying degrees, and what this model allows us to do, with the help of the HeXie dimension, is to re-balance after a disruption. Importantly, re-balance refers here to a new equilibrium, which is never the same as the equilibrium that existed prior to the disruption but which may offer new ways of imagining learning and teaching that is both fit for purpose and fit of purpose [86].

\section{Conclusions}

This paper focuses on the critical role of self-directed learning and digital resilience where both teachers and students are key stakeholders as the co-creators of the digital learning ecology across the microsystem, mesosystem, exosystem, macrosystem, and chronosystem.

\subsection{Implications}

Our study contributes to the emerging literature on digital learning ecology $[43,119]$ by providing a holistic view that across five ecosystems, while prior studies have made significant contributions in exploring the learning ecology within specific ecosystem. Borge and Mercier developed a micro-ecological framework with a focus on the microanalysis of individual interactions when different cognitive systems interact and modify different learning activities [120]. Further, the University of Illinois has worked on a digital learning ecology where computers are used as mediators in social human connections, as "computers could not simply be applied to education. It had to be (re)designed to align with the social construction that is education" [121]. Van den Beemt and Diepstraten reinforced 
the importance of the creation of information and communication technology rich social environments in a exo-level learning ecology [122].

Regarding the practical implications, this study has proposed two new constructs: self-directed learning and digital resilience within a digital learning ecology, which may inspire new directions into digital learning analysis, for example, exploratory structure equation modelling through quantitative grounded theory. In terms of learning and teaching practices, the proposed conceptual model might serve as a framework to promote new educational development policy and may encourage innovative pre-sessional and syntegrative programmes for students as well as more effective and agile professional development programmes for teachers.

More importantly, the proposed digital learning HeXie ecology model allows us to conceptualise learning across formal, informal, and lifelong learning in different levels of human ecology, and what is needed in a learning environment in response to and in the aftermath of a major disruption. The main contribution to the current literature is that the proposed model has extended Kek and Huijser [13] PBL ecology for learning by adding another layer in the form of the Chinese HeXie concept. This allows us to find a new equilibrium (or indeed, new equilibria) in relation to student learning.

\subsection{Limitations and Future Development}

At this stage, this paper has been conceived on a purely conceptual level. Although applying these ideas in practice is more complex, an increasing number of future-oriented universities have made varying degrees of progress [23,39]. Future studies are therefore encouraged to test this model by applying it empirically in different contexts, such as by examining the association between students' self-directed learning ability and their digital resilience in a syntegrative education system based on industry-university partnerships and in the process testing the influence of teacher support for student self-directed learning and digital resilience development in formal and informal learning environments.

Author Contributions: Conceptualization, N.L., H.H. and Y.X.; methodology, N.L.; writing-original draft preparation, N.L. and H.H.; writing-review and editing, Y.X., M.L., X.Z. and M.Y.C.A.K.; visualization, N.L. and Y.X.; supervision, X.Z., Y.X. and M.L.; project administration, N.L.; funding acquisition, M.L. and N.L. All authors have read and agreed to the published version of the manuscript.

Funding: This research was funded by the University of Liverpool, grant number 100699618.

Institutional Review Board Statement: Not applicable.

Informed Consent Statement: Not applicable.

Data Availability Statement: Not applicable.

Acknowledgments: We thank the editors and the two anonymous reviewers for providing informative and insightful comments to help strengthen the manuscript. We thank the editorial office and the MDPI service team for providing professional and efficient support.

Conflicts of Interest: The authors declare no conflict of interest.

\section{References}

1. Schwab, K. The Fourth Industrial Revolution: What It Means, How to Respond. 2016. Available online: https://www.weforum. org/agenda/2016/01/the-fourth-industrial-revolution-what-it-means-and-how-to-respond (accessed on 2 November 2020).

2. Schwab, K. World Economic Forum. 2018. Available online: https://www.weforum.org/agenda/2018/11/globalization-4-whatdoes-it-mean-how-it-will-benefit-everyone (accessed on 6 November 2020).

3. Salmon, G. May the fourth be with you: Creating education 4.0. J. Learn. Dev. 2019, 6, 95-115.

4. Williams, A.R.; Windle, R.; Wharrad, H. How will Education 4.0 influence learning in higher education? J. Learn. Dev. High. Educ. 2020, 1-18. [CrossRef]

5. Collins, A.; Halverson, R. Rethinking Education in the Age of Technology; Teachers College Press: New York, NY, USA, 2008.

6. Means, A.J. Learning to Save the Future: Rethinking Education and Work in an Era of Digital Capitalism; Routledge: New York, NY, USA, 2018. 
7. Green, W.; Anderson, V.; Tait, K.; Tran, L.T. Precarity, fear and hope: Reflecting and imagining in higher education during a global pandemic. High. Educ. Res. Dev. 2020, 39, 1309-1312. [CrossRef]

8. Baber, H. Determinants of students' perceived learning outcome and satisfaction in online learning during the pandemic of COVID-19. J. Educ. E-Learn. Res. 2020, 7, 285-292. [CrossRef]

9. Kumar, P.; Saxena, C.; Baber, H. Learner-content interaction in e-learning-the moderating role of perceived harm of COVID-19 in assessing the satisfaction of learners. Smart Learn. Environ. 2021, 8, 1-15. [CrossRef]

10. Leask, B. Embracing the possibilities of disruption. High. Educ. Res. Dev. 2020, 39, 1388-1391. [CrossRef]

11. Greener, S.L. COVID-19: A stimulus to 2020 vision. Interact. Learn. Environ. 2020, 28, 656-657. [CrossRef]

12. Sangrá, A.; Raffaghelli, J.E.; Guitert-Catasús, M. Learning Ecologies through a Lens: Ontological, Methodological and Applicative Issues. A Systematic Review of the Literature. Br. J. Educ. Technol. 2019, 50, 1619-1638. [CrossRef]

13. Kek, M.Y.C.A.; Huijser, H. Problem-Based Learning into The Future: Imagining an Agile Pbl Ecology for Learning; Springer: Singapore, 2017. [CrossRef]

14. Jackson, N. Exploring Learning Ecologies; Chalk Mountain: Surrey, UK, 2016.

15. Cunha, M.N.; Chuchu, T.; Maziriri, E.T. Threats, Challenges, And Opportunities for Open Universities and Massive Online Open Courses in The Digital Revolution. Int. J. Emerg. Technol. Learn. 2020, 15, 191-204. [CrossRef]

16. Koh, J.H.L.; Kan, R.Y.P. Students' use of learning management systems and desired e-learning experiences: Are they ready for next generation digital learning environments? High. Educ. Res. Dev. 2020, 40, 995-1010. [CrossRef]

17. Barana, A.; Marchisio, M. Analyzing Interactions in Automatic Formative Assessment Activities for Mathematics in Digital Learning Environments. In Proceedings of the 13th International Conference on Computer Supported Education, Online, 23-25 April 2021; 2021; pp. 497-504.

18. Teo, T.C.; Divakar, A. Understanding the concepts of digital learning approaches: An empirical analysis of schools in developing countries. J. Appl. Learn. Teach. 2021, 4, 120-128.

19. Zaman, U.; Aktan, M.; Baber, H.; Nawaz, S. Does forced-shift to online learning affect university brand image in South Korea? Role of perceived harm and international students' learning engagement. J. Mark. High. Educ. 2021, 1-25. [CrossRef]

20. Chou, Y.Y.; Wu, P.F.; Huang, C.Y.; Chang, S.H.; Huang, H.S.; Lin, W.M.; Lin, M.L. Effect of Digital Learning Using Augmented Reality with Multidimensional Concept Map in Elementary Science Course. Asia-Pac. Educ. Res. 2021, 1-11. [CrossRef]

21. Mustapha, R.; Jafar, M.F.; Othman, M.M.; Jusoh, M.K.; Ibrahim, N.S. The Development of I-Cylearn Framework in Online Digital Learning in Higher Education: The Fuzzy Delphi Method Study. Int. J. Acad. Res. Bus. Soc. Sci. 2021, 11, 412-428. [CrossRef]

22. Brown, M.; McCormack, M.; Reeves, J.; Brooks, D.C.; Grajek, S.; Alexander, B.; Bali, M.; Bulger, S.; Dark, S.; Engelbert, N.; et al. 2020 EDUCAUSE Horizon Report, Teaching and Learning Edition; EDUCAUSE: Louisville, CO, USA, 2020.

23. Xi, Y. Noteworthy Conduct and Independent Character: The Way of Hexie Education; Qinghua University Press: Beijing, China, 2021.

24. Dearing, R. National Committee of Inquiry into Higher Education (NCIHE) Higher Education in the Learning Society. In Report of the National Committee of Enquiry into Higher Education; HMSO: London, UK, 1997.

25. Jaakkola, E. Designing conceptual articles: Four approaches. AMS Rev. 2020, 10, 18-26. [CrossRef]

26. Weick, K.E. Theory Construction as Disciplined Imagination. Acad. Manag. Rev. 1989, 14, 516-531. [CrossRef]

27. Marsick, V.J.; Watkins, K. Informal and Incidental Learning in the Workplace; Routledge: London, UK, 2015.

28. Coombs, P.H.; Ahmed, M. How Nonformal Education Can Help; Johns Hopkins University Press: Baltimore, MD, USA, 1974.

29. Nye, A.; Clark, J. Teaching History for the Contemporary World-Tensionns, Challenges and Classroom Experiences in Higher Education; Springer Nature Singapore Pte Ltd.: Singapore, 2021.

30. Britain, S.; Liber, O. A Framework for Pedagogical Evaluation of Virtual Learning Environments; University of Wales: Bangor, UK, 1999.

31. Piccoli, G.; Ahmad, R.; Ives, B. Web-Based Virtual Learning Environments: A Research Framework and a Preliminary Assessment of Effectiveness in Basic IT Skills Training. MIS Q. 2001, 25, 401-426. [CrossRef]

32. McGuire, D.; Gubbins, C. The Slow Death of Formal Learning: A Polemic. Hum. Resour. Dev. Rev. 2010, 9, 249-265. [CrossRef]

33. Guile, D.; Griffith, T. Learning through work experience. J. Educ. Work 2001, 14, 113-131. [CrossRef]

34. Svensson, L.; Ellstrom, P.E.; Aberg, C. Integrating formal and informal learning at work. J. Workplace Learn. 2004, 16, 479-491. [CrossRef]

35. Ebner, M.; Schön, S.; Braun, C.; Ebner, M.; Grigoriadis, Y.; Haas, M.; Leitner, P.; Taraghi, B. COVID-19 Epidemic as E-Learning Boost? Chronological Development and Effects at an Austrian University against the Background of the Concept of "E-Learning Readiness". Future Internet 2020, 12, 94. [CrossRef]

36. Flavin, M. Re-Imagining Technology Enhanced Learning-Critical Perspectives on Disruptive Innovation; Springer Nature: London, UK, 2020.

37. Li, N.; Wang, Q.; Liu, J.; Marsick, V. Improving Interdisciplinary Online Course Design Through Action Learning: A Chinese Case Study. Action Learn. Res. Pract. 2021, 1-16. [CrossRef]

38. Antee, A. Student perceptions and mobile technology adoption: Implications for lower-income students shifting to digital. Educ. Technol. Res. Dev. 2020, 69, 423-432. [CrossRef] [PubMed]

39. Pelletier, K.; Brown, M.; Brooks, D.C.; McCormack, M.; Reeves, J.; Arbino, N.; Bozkurt, A.; Crawford, S.; Czerniewicz, L.; Gibson, R.; et al. 2021 EDUCAUSE Horizon Report, Teaching and Learning Edition; EDUCAUSE Publications: Boulder, CO, USA, 2021.

40. Huang, R.; Spector, J.M.; Yang, J. Educational Technology: A Primer for the 21st Century; Lecture Notes in Educational Technology; Huang, R., Kinshuk, M., Jemni, N., Chen, N.-S., Spector, J.M., Eds.; Springer Nature Singapore Pte Ltd: Singapore, 2019. 
41. Osmani, M.; Weerakkody, V.; Hindi, N.; Eldabi, T. Graduates employability skills: A review of literature against market demand. J. Educ. Bus. 2019, 94, 423-432. [CrossRef]

42. Barari, N.; RezaeiZadeh, M.; Khorasani, A.; Alami, F. Designing and validating educational standards for E-teaching in virtual learning environments (VLEs), based on revised Bloom's taxonomy. Interact. Learn. Environ. 2020, 1-13. [CrossRef]

43. Huijser, H.; Kek, M.Y.C.A.; Abawi, L.; Lawrence, J. Leveraging creativity to engage students in an agile ecology for learning. Stud. Engagem. High. Educ. J. 2019, 2, 138-153.

44. Christensen, C.M.; Horn, M.B.; Johnson, C.W. Disrupting Class: How Disruptive Innovation Will Change the Way the World Learns, McGraw Hill: New York, NY, USA, 2008.

45. Alghatrifi, I. Factors affecting emerging technology adoption in higher education: A systematic mapping study. Open Int. J. Inform. 2019, 7, 147-157.

46. Blin, F.; Munro, M. Why hasn't technology disrupted academics' teaching practices? Understanding resistance to change through the lens of activity theory. Comput. Educ. 2008, 50, 475-490. [CrossRef]

47. Selwyn, N. The use of computer technology in university teaching and learning: A critical perspective. J. Comput. Assist. Learn. 2007, 23, 83-94. [CrossRef]

48. Flavin, M. Disruptive conduct: The impact of disruptive technologies on social relations in higher education. Innov. Educ. Teach. Int. 2016, 53, 3-15. [CrossRef]

49. Keller, C. Virtual Learning Environments: Three Implementation Perspectives. Learn. Media Technol. 2005, 30, 299-311. [CrossRef]

50. UCL. ABC LD learning types and tools V3 2020 UCL; UCL: London, UK,, 2020.

51. Blundell, C.; Lee, K.-T.; Nykvist, S. Moving beyond enhancing pedagogies with digital technologies: Frames of reference, habits of mind and transformative learning. J. Res. Technol. Educ. 2020, 52, 178-196. [CrossRef]

52. Rahman, M.K.U.; Haleem, F. Information and communication technology workforce employability, Khyber Pukhtunkhwa, Pakistan. Middle East J. Bus. 2018, 13, 12-16. [CrossRef]

53. Lopes, R.M.; Faria, D.J.G.d.S.d.; Fidalgo-Neto, A.A.; Mota, F.B. Facebook in educational research: A bibliometric analysis Scientometrics 2017, 111, 1591-1621. [CrossRef]

54. McGunagle, D.; Zizka, L. Employability skills for 21st-century STEM students: The employers' perspective. High. Educ. Ski. Work-Based Learn. 2020, 10, 591-606. [CrossRef]

55. Demaria, M.; Hodgson, Y.; Czech, D. Perceptions of transferable skills among biomedical science students in the final year of their degree: What are the implications for graduate employability? Int. J. Innov. Sci. Math. Educ. 2018, 26, 11-24.

56. del Cerro Santamaria, G. Challenges and drawbacks in the marketisation of higher education within neoliberalism. Rev. Eur. Stud. 2020, 12, 22-38. [CrossRef]

57. McCaig, C. The Marketisation of English Higher Education: A Policy Analysis of a Risk-Based System; Emerald Publishing Limited: Bingley, UK, 2018.

58. Robbins, L. Higher Education. Report of the Committee Appointed by the Prime Minister under the Chairmanship of Lord Robbins (Cmnd. 2154). 1963. Available online: http://www.educationengland.org.uk/documents/robbins/index.html (accessed on 6 November 2020).

59. Deem, R. The knowledge worker, the manager-academic and the contemporary UK University: New and old forms of public management. Financ. Account. Manag. 2004, 20, 107-128. [CrossRef]

60. Schuller, T. The Changing University? Taylor \& Francis: Bristol, UK, 1995.

61. Williams, G. The market route to mass higher education: British experience 1979-1996. High. Educ. Policy 1997, 10, 275-289. [CrossRef]

62. Daniel, J.S. Open Universities: Old Concepts and Contemporary Challenges. Int. Rev. Res. Open Distrib. Learn. 2019, 20, 196-211. [CrossRef]

63. Eesley, C.; Li, J.B.; Yang, D. Does Institutional Change in Universities Influence High-Tech Entrepreneurship? Evidence from China's Project 985. Organization Science. 2016, 27, 446-461. [CrossRef]

64. Li, A.J. The explorement of building innovation and entrepreneur of colleges and universities education model based on career planning. China Univ. Stud. Career Guide 2017.

65. Rook, L.; McManus, L. Responding to COVID-19: Enriching students' responsible leadership through an online work-integrated learning project. Int. J. Work-Integr. Learn. 2020, 21, 601-616.

66. Sousa, M.d. Reimaging Our Futures Together-A New Social Contract for Education; United Nations Educational, Scientific and Cultural Organization: Paris, France, 2021.

67. Huijser, H.; Fitzgerald, R. Managing expectations and developing trust: An evaluation of a public-private partnership. Australas. J. Educ. Technol. 2020, 36, 58-70. [CrossRef]

68. Hornsby, D.J.; Osman, R. Massification in higher education: Large classes and student learning. High. Educ. 2014, 67, 711-719. [CrossRef]

69. Hannafin, M.; Hill, J.; Land, S. Student-centered learning and interactive multimedia: Status, issues, and implications. Contemp. Educ. 1997, 68, 94-99.

70. Cannon, R.; Newble, D. A Handbook for Teachers in Universities and Colleges. A Guide to Improving Teaching Methods; Kogan Page: London, UK, 2000. 
71. Lea, S.; Stephenson, D.; Troy, J. Higher education students' attitudes to student-centred learning: Beyond educational bulimia? Stud. High. Educ. 2003, 28, 321-334. [CrossRef]

72. Vermetten, Y.; Vermunt, J.; Lodewijks, H. Powerful learning environments? How university students differ in their response to instructional measures. Learn. Instr. 2002, 12, 263-284. [CrossRef]

73. Czaplinski, I. An Analysis of Learning Networks of Stem Undergraduate Students to Promote Active Learning. Doctoral Dissertation, Queensland University of Technology, Brisbane, Australia, 2020.

74. Zhang, X.; Xi, Y. University Transformation-from Teacher-Dominated to Student-Centered; Qinghua University Press: Beijing, China, 2021.

75. Ladson-Billings, G. I'm here for the hard re-set: Post pandemic pedagogy to preserve our culture. Equity Excell. Educ. 2021, 54, 68-78. [CrossRef]

76. Rai, A. Editor's Comments: The COVID-19 Pandemic: Building Resilience with IS Research. MIS Q. 2020, 44, iii-vii.

77. Tough, A. The Adult's Learning Projects; Ontario Institute for Studies in Education: Toronto, ON, Canada, 1971.

78. Brockett, R.G.; Hiemstra, R. Self-Direction in Adult Learning: Perspectives on Theory, Research, and Practice; Routledge: New York, NY, USA, 1991.

79. Shapley, P. On-line education to develop complex reasoning skills in organic chemistry. J. Asynchronous Learn. Netw. 2000, 4 , 43-49. [CrossRef]

80. Knowles, M.S. Self-Directed Learning: A Guide for Learners and Teachers; Association Press: New York, NY, USA, 1975.

81. Long, H.B. Trends in Self-Directed Learning Research Paradigms. In Emerging Directions in Self-Directed Learning, Derrick, M.G., Ponton, M.K., Eds.; Discovery Association Publishing House: Chicago, IL, USA, 2009; pp. 19-36.

82. Tough, A. The Adult's Learning Projects: A Fresh Approach to Theory And Practice In Adult Learning; The Ontario Institute for Studies in Education: Toronto, ON, Canada, 1979.

83. Guglielmino, L.M. Development of the Self-Directed Learning Readiness Scale; University of Georgia: Athens, GA, USA, 1977.

84. Carré, P.; Jézégou, A.; Kaplan, J.; Cyrot, P.; Denoyel, N. L'Autoformation: The State Of Research On Self- (Directed) Learning In France. Int. J. Self-Dir. Learn. 2011, 8, 7-17.

85. Van der Walt, J.L. The Term "Self-Directed Learning"—Back to Knowles, or Another Way to Forge Ahead? J. Res. Christ. Educ. 2019, 28, 1-20. [CrossRef]

86. Scott, G. Engaging and retaining students in productive learning. In Student Support Services: Their Impact on Student Engagement, Experience and Learning; Huijser, H., Kek, M.Y.C.A., Padró, F., Eds.; Springer: Singapore, 2021.

87. Bronfenbrenner, U. The Ecology of Human Development: Experiments by Nature and Design; Harvard University Press: Cambridge, MA, USA, 1979

88. Carré, P. The double dimension of self-directed learning: Learners experiment with freedom. Int. J. Self-Dir. Learn. 2012, 9, 1-10.

89. Yavuzalp, N.; Bahcivan, E. A structural equation modeling analysis of relationships among university students' readiness for e-learning, self-regulation skills, satisfaction, and academic achievement. Res. Pract. Technol. Enhanc. Learn. 2021, 16, 1-17. [CrossRef]

90. Kirschner, P.; van Merriënboer, J.J.G. Do learners really know best? Urban legends in education. Educ. Psychol. 2013, 48, 169-183. [CrossRef]

91. Rojas, F.J. Understanding Faculty Resistance to Change in Adopting Online Degree Programs. Doctoral Dissertation, Fielding Graduate University, Santa Barbara, CA, USA, 2020.

92. Limniou, M. The Effect of Digital Device Usage on Student Academic Performance: A Case Study. Educ. Sci. 2021, 11, 121. [CrossRef]

93. Virtanen, M.A.; Haavisto, E.; Liikanen, E.; Kääriäinen, M. Ubiquitous learning environments in higher education: A scoping literature review. Educ. Inf. Technol. 2018, 23, 985-998. [CrossRef]

94. Raza, S.A.; Qazi, W.; Khan, K.A.; Salam, J. Social Isolation and Acceptance of the Learning Management System (LMS) in the time of COVID-19 Pandemic: An Expansion of the UTAUT Model. J. Educ. Comput. Res. 2020, 59, 1-26. [CrossRef]

95. Fawns, T.; Jones, D.; Aitken, G. Challenging assumptions about "moving online" in response to COVID-19, and some practical advice. Med. Ed. Publ. 2020, 9, 83. [CrossRef]

96. Watermeyer, R.; Crick, T.; Knight, C.; Goodall, J. COVID-19 and digital disruption in UK universities: Afflictions and affordances of emergency online migration. High. Educ. 2020, 81, 623-641. [CrossRef] [PubMed]

97. Zhang, W.; Wang, Y.; Yang, L.; Wang, C. Suspending Classes Without Stopping Learning: China's Education Emergency Management Policy in the COVID-19 Outbreak. J. Risk Financ. Manag. 2020, 13, 55. [CrossRef]

98. Raviola, E.; Norbäck, M. Bringing Technology and Meaning into Institutional Work: Making News at an Italian Business Newspaper. Organ. Stud. 2013, 34, 1171-1194. [CrossRef]

99. Li, N.; Zhang, X.; Limniou, M. A country's national culture affects virtual learning environment adoption in higher education: A systematic review (2001-2020). Interact. Learn. Environ. 2021, 1-19. [CrossRef]

100. Tan, C. Confucius. Bloomsbury Library of Educational Thought; Bailey, R., Ed.; Bloomsbury: London, UK.

101. Corcoran, C. Chinese learning styles: Blending Confucian and Western theories. J. Instr. Pedagog. 2014, 13, 1-10.

102. Jing, R.; Van de Ven, A.H. A Yin-Yang Model of Organizational Change: The Case of Chengdu Bus Group. Manag. Organ. Rev. 2014, 10, 29-54. [CrossRef]

103. Xi, Y.M.; Ge, J. HeXie Management Theory: Case Studies and Application; Xi'an Jiaotong University Press: Xi'an, China, 2005. 
104. Xi, Y.; Zhang, X.; Ge, J. Replying to management challenges: Integrating oriental and occidental wisdom by HeXie Management Theory. Chin. Manag. Stud. 2012, 6, 395-412. [CrossRef]

105. Luan, S.; Reb, J.; Gigerenzer, G. Ecological Rationality: Fast-and-Frugal Heuristics for Managerial Decision Making under Uncertainty. Acad. Manag. J. 2019, 62, 1735-1759. [CrossRef]

106. Greenwood, R.; Raynard, M.; Kodeih, F.; Micelotta, E.R.; Lounsbury, M. Institutional complexity and organizational responses. Acad. Manag. Ann. 2011, 5, 317-371. [CrossRef]

107. Dweck, C.S. Mindset: The New Psychology of Success; Penguin Random House LLC: New York, NY, USA, 2006.

108. Ellis, R.A.; Goodyear, P. Spaces of Teaching and Learning Integrating Perspectives on Research and Practice; Springer: Singapore, 2018.

109. Heo, J.; Han, S. The mediating effect of literacy of LMS between self-evaluation online teaching effectiveness and self-directed learning readiness. Educ. Inf. Technol. 2021, 26, 6097. [CrossRef]

110. Bond, M.; Bedenlier, S. Facilitating Student Engagement Through Educational Technology: Towards a Conceptual Framework. J. Interact. Media Educ. 2019, 1, 1-14. [CrossRef]

111. Adhikari, J.; Mathrani, A.; Scogings, C. Bring Your Own Devices classroom. Interact. Technol. Smart Educ. 2016, 13, 323-343. [CrossRef]

112. Warschauer, M.; Xu, Y. Technology and Equity in Education; Voogt, J., Knezek, G., Christensen, R., Eds.; Springer International Publishing: Cham, Switzerland, 2018.

113. Limniou, M.; Varga-Atkins, T.; Hands, C.; Elshamaa, M. Learning, Student Digital Capabilities and Academic Performance over the COVID-19 Pandemic. Educ. Sci. 2021, 11, 361. [CrossRef]

114. Vaujany, F.-X.d.; Adrot, A.; Boxenbaum, E.; Leca, B. Materiality in Institutions: Spaces, Embodiment and Technology in Management and Organization; Technology, Work and Globalization; Palgrave Macmillan: Cham, Switzerland, 2019.

115. Perry-Smith, J.; Shalley, C. The Social Side of Creativity: A Static and Dynamic Social Network Perspective. Acad. Manag. Rev. 2003, 28, 89-106. [CrossRef]

116. Gibbons, R. Game Theory for Applied Economists; Princeton University Press: Princeton, NJ, USA, 1992.

117. Beer, S. Diagnosing the System for Organizations; Wiley: London, UK, 1985.

118. Kaufman, R. Planning Educational Systems: A Results-Based Approach; Technomic: Lancaster, PA, USA, 1988.

119. Reyna, J. Digital Teaching and Learning Ecosystem (DTLE): A Theoretical Approach for Online Learning Environments. In Proceedings of the Australian Society for Computers in Learning in Tertiary Education Annual Conference, Hobart, Tasmania, Australia, 4-7 December 2011.

120. Borge, M.; Mercier, E. Towards a micro-ecological approach to CSCL. Int. J. Comput. Supported Collab. Learn. 2019, 14, 219-235. [CrossRef]

121. Dragonas, T.; Gergen, K.J.; McNamee, S.; Tseliou, E. Education as Social Construction-Contributions to Theory, Research and Practice; Taos Institute Publications/WorldShare Books: Chagrin Falls, OH, USA, 2015.

122. Van den Beemt, A.; Diepstraten, I. Teacher perspectives on ICT: A learning ecology approach. Comput. Educ. 2016, 92-93, 161-170. [CrossRef] 